https://doi.org/10.7250/scee.2021.0010

\title{
THE ROLE OF AUDIENCE SEGMENTS ON MEDIA CONSUMPTION
}

\author{
Linda SAULITE \\ Riga Technical University, Riga, Latvia \\ Corresponding author e-mail: Linda.Saulite_1@edu.rtu.lv
}

\begin{abstract}
The research aims to present the role of the media brand associations on media content consumption by Generation $Z$. Technological convergence and content distribution and accessibility via multi- platforms brought new patterns in media content consumption regarding volume, channel, device and time. Digitalisation and technology advancement brought utterly new aspects in media consumption. Due to accessibility, content is distributed and consumed via multiple platforms. Convergence between different demand and supply channels makes content consumption easier in the meantime; content supply becomes more cluttered with new media entering the market. Social network sites created new possibilities for content distribution, readership, branding. Content consumption on-demand and via multi-platforms bring not only possibilities for media brands but also challenges. Media brands should reinvent their branding strategies as content consumption via multi-platforms dilutes brand associations, and therefore more and more of the audience becoming indifferent to media brands and more focused on content experience. Jenkins (2008) referred that consumers content consumption behaviour now is mobile, non-linear, modular, and not device/outlet/platform dependent. The main impact of the increasing audience fragmentation, the development of distribution channels, and the advancement of technology that allows for time and platform shifting according to the audience's immediate needs all contribute to an environment where the value of media brand or channel branding is valued might be diminishing. For Generation $\mathrm{Z}$, this behaviour is even more pronounced as they consume traditional media below average and prefer media content on online platforms, access online content via mobile devices, use social media more than other age groups and choose international media and social network platforms over local media content. Changes create difficulties for national media brands to attract and grow the future audience - Generation $\mathrm{Z}$. This audience use less local media content, use less media content in their national language, and consume it via social media platforms. The author analyses the consumption trends of national media brands in Latvia and highlights the significant brand associations that positively impact media brand content consumption for a younger media audience. The research shows that the distinctive content seamless and appropriate content experience to each consumption platform positively influences and strengthens media brand associations and, therefore, increase media brand usage. The more the target audience feels connected, engaged and associated with the media brand community, the more it feels towards the media brand. Thus, the research confirms many scholars findings that audience becomes a significant part of media brand and interaction or content experience is crucial for building media brand associations.
\end{abstract}

Keywords: Content experience, Media brand, Media brand associations, Media consumption 
JEL Classification: M31

\section{INTRODUCTION}

Digitalisation and technological advancement changed information supply and demand ways in many industries. (Eremina, Lace, Bistrova, 2019) noted that digitalisation processes have accelerated all industries' development by connecting, fast, and controllable while also providing easy access to data and necessary information. This also applies to media companies highly impacted by digitalisation and social media network development worldwide. In the last fifteen years of academic research on media brands and branding, two aspects dominate when researching the digitalisation process impact on media brands: technological convergence resulting in content consumption on-demand via multiple platforms and audience fragmentation due to development and popularity of social media platforms and increasing content consumption access points.

\section{MEDIA BRAND CONTENT CONSUMPTION CHANGES AND ITS EFFECT ON THE MEDIA BRAND}

The development of technologies brought significant changes to how the audience consumes media content. Chan-Olmsted (2011) stated that with the increase of connected devices, the focus is on the act of consumption, not the devices or access points. Jenkins (2008) states that today's media audience, especially the younger audience, requires a media content consumption experience that is mobile, non-linear, modular and not the device, platform or outlet dependent.

The primary changes directly influence media brand content distribution and consumption:

- a shift from traditional media to a digital environment media content consumption.

- media content consumption on-demand via multiple platforms.

- media content consumption via social media platforms.

According to Saulite et al. (2020), technological convergence and content distribution and accessibility via multi- platforms brought new patterns in media content consumption regarding volume, channel, device and time. Social network sites created new possibilities for content distribution, readership, branding. Increasing usage of global social network sites brings opportunities for media brands to distribute content and reach the audience and new challenges and competition for local and national media. Content consumption on-demand and via multi-platforms bring not only possibilities for media brands but also challenges. The growing multichannel, multimedia marketing environment presented a new layer of brand management challenges to media branding (Chan-Olmsted, 2011, p. 3-19). According to ChanOlmsted (2011) from a macro perspective, this meant media brands had to ensure their products and content were synergistic across different media and channels, in the meantime taking advantage of each medium's unique characteristics.

The author analyses the consumption trends of national media brands in Latvia. The research aims to define media brand associations that positively impacts media brand consumption by Generation $\mathrm{Z}$ in the convergent and multi-platform marketplace 
focusing on news media and measuring content unrelated brand associations that increase media brand usage and engagement for a younger audience.

\section{METHODOLOGY}

First, to confirm media consumption changes in Latvia influenced by digitalisation and technology advancement, the author used a secondary research method. The research framework is based on secondary data, quantitative consumer research done every two years from 2012 till 2021 by SIA Dentsu Aegis Network Latvia. At this media agency, the author holds a member of the board and managing director position, and the author responsibilities include quantitative consumer research management. Data is updated every two years, conducted in 65 countries, including Latvia. The data collection method is an online interview with a length of 90 minutes. The questionaries include online and offline activities, favourite channels and platforms, media reach and impact. Research simple size in Latvia is 3163 , using nationally representative sample and quota by socio-demographics and internet usage. The research consists of fieldwork in the length of three months and data analyses.

Second, using consumer-based brand equity framework and news media aspects and media consumption data that support research actuality, the author used quantitative research, survey research, a sample size of 300 respondents aged 15-24 years, weighted data in Latvia in May- June 2018. The author chose the most used local news media brands aged 15-24 to determine non-product related brand associations that increase media brand consumption and engagement. The research built on choice questionaries to determine how Generation $\mathrm{Z}$ uses national media and access particular media brands. The research aim was to find the media brand associations that first influence media brand choice, then increase usage and engagement with the brand. The fieldwork and data analyses were done over two months, May - June 2018. First, the responders graded the importance of selected brand associations that increase content consumption, engagement and following social networks. Then the data were analysed and correlated between the main product and non-product associations determined to observe variables to establish a statistically corresponding relationship between them]. The aim was to identify variables that have some ties to create some change in the other.

\section{RESULTS. THE SHIFTING PARADIGMS IN MEDIA CONSUMPTION}

\section{From traditional media to a digital environment, content consumption}

The digitalisation process impact on media brands brought technological convergence between different media outlets. Development of technologies and internet accessibility increase audience volume that access content online and consume it daily. In 2020 regular internet users (use at least one time per week) in Latvia increased by $3.2 \%$ compared to 2019 and reached $86.9 \%$ of the population. In the age group 16-24 y.o, the regular internet users reach $97.9 \%$ of this age group. In the age group 25-54 y.o, this data is $95.2 \%$, but in the age group 55-74 y.0. 69.6\% (Dentsu Aegis Network Latvia, 2020). 81.7\% of all internet users in online environments read online news media, print or magazine online versions. The most popular online activities for younger audiences $(16-24$ y.o.) are social media platforms, instant messaging, and email services (Dentsu Aegis Network Latvia, 2020). Following this, 
the content consumption from traditional forms like TV, Radio, Print moves to the online environment. If we compare the share of time spent by media type, online media content consumption increased from $27 \%$ in 2014 to $44 \%$ in 2021 (see Fig. 1).

TV $\backsim$ Online $\square \mathrm{OOH} \square$ Radio $\square$ Print
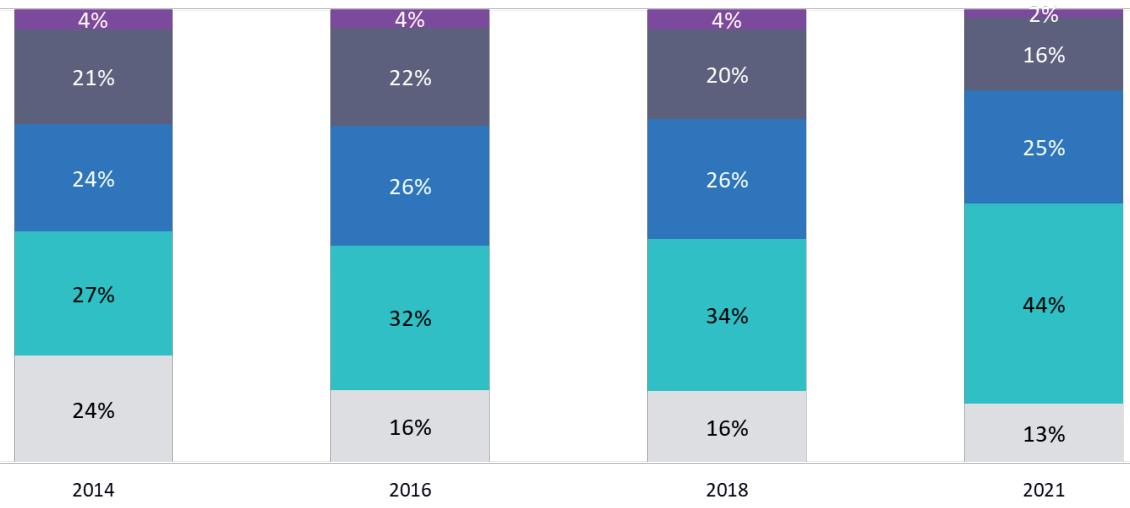

Fig. 1. Share of time spent with media 2014 - 2021, base: All 15-64, Latvia, (Consumer Connection System, Dentsu Aegis Network Latvia)

Meanwhile, traditional media content consumption timeshare like radio decreased from $21 \%$ in 2014 to $16 \%$ in 2021 . Likewise, time spent with TV media decreased from 24\% in 2014 to $13 \%$ in 2021(Dentsu Aegis Network Latvia, 2021). Data confirms the shift in content consumption from traditional media forms to online consumption in all age groups. (Dentsu Aegis Network Latvia, 2021) Also, the data can be interpreted as an assumption of decreasing TV or Radio content usage or decreasing time with media; the opposite is true. In 2016, on average, a person in Latvia consumed media 12 hours 1 minute per day, while in 2014 - only 9 hours 55 minutes hours per day (Dentsu Aegis Network Latvia, 2016). Accessibility and technologies increased audiences' time with media, but how the audience consumes media content changed from traditional to online.

\section{Content consumption on-demand via multiple devices and channels}

Media consumption across the globe is increasingly happening in digital formats. The increase in the number of devices capable of supporting digital media and increasing internet access speed has provided consumers with an option to access the media content of their choice, be it information, entertainment or social activity anytime, anywhere (Deloitte Touche Tohmatsu India Private Limited, 2015).

In the TV audience analyses, the content consumption patterns of the TV audience, the time-shifted viewing and video-on-demand content consumption are growing in Latvia. Linear TV content consumption means that the audience watches a TV program on the channel it is presented on at its scheduled time. In terms of daily reach, Linear TV audience reach decreased from $81 \%$ in 2012 to $65 \%$ in 2021 . The monthly and weekly reach decreased slightly less (Dentsu Aegis Network Latvia, 2021).

The younger the audience, the less this audience linearly consume TV content. In $202170 \%$ of the audience age group, 15-24 y.o. is reached weekly via Liner TV, compering to reach $79 \%$ of this audience in 2012 weekly (Dentsu Aegis Network Latvia, 2021). Increasing audience data on time-shifted and on-demand TV content 
viewing shows audience need for not a device, platform or outlet dependent media content consumption. Time-shifting is the recording of programming to a storage medium to be viewed or listened to after the live broadcasting. TV content consumption on-demand is growing in all age group audience segments. The younger the audience, the higher content usage is on-demand. In 2021 weekly reach of this age group is $70 \%$
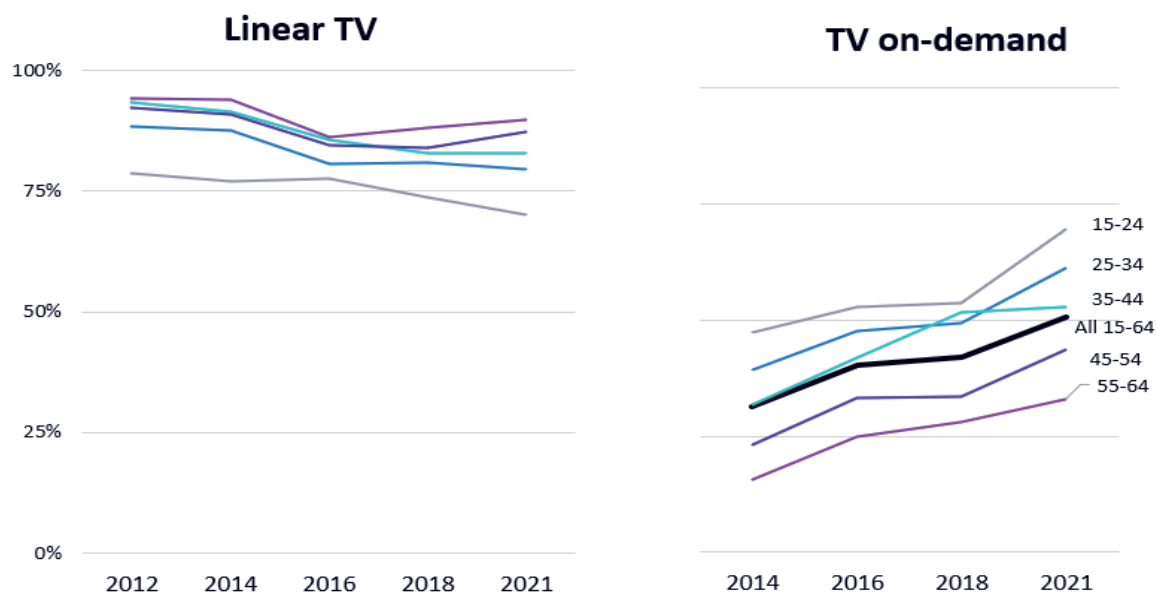

compared to $47 \%$ in 2014 . For all $15-64$ y.o. audience in Latvia weekly reach consuming media content on-demand is $51 \%$ in 2021 , compering to $32 \%$ in 2014 (see Fig. 2).

Fig. 2. The linear TV and TV on-demand weekly reach by ages groups, Latvia, 20142021, base: all 15-64 (Consumer Connections System, Dentsu Aegis Network Latvia, 2021)

The content consumption on-demand also increases in radio media audience. Radio media audience reach remains stable over time with growing audience share streaming music on paid or free platforms - $28 \%$ of all audience streaming music daily in 2021 compering to $16 \%$ in 2016 . Content consumption via streaming platforms depends on the age group where younger audience 15-24 y.o. consumes content at a significantly higher level $-55 \%$ of this age group consume weekly content while others are below $40 \%$ in 2021 (see Fig. 3).

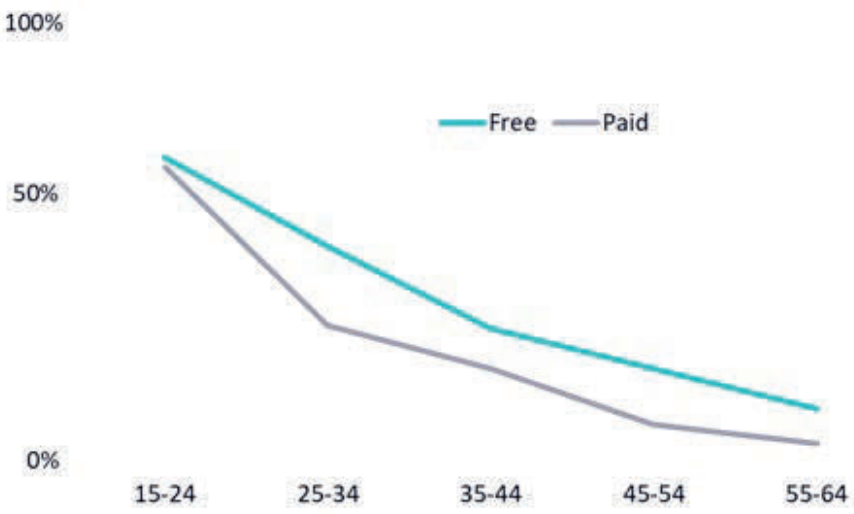

Fig. 3. The radio streaming weekly reach by age groups, Latvia, 2021, base: all 15-64 (Consumer Connections System, Dentsu Aegis Network Latvia, 2021) 
The digitalisation of media content consumption is present in all age groups of media audiences. Moreover, technology development and accessibility let audiences consume content on their terms independently from programming times, platforms and devices.

The development of technologies and social media platforms changed how media brand content is distributed and consumed by the audience. Categorising media brands depends on the aspect of how is a look at on media products. Media brand product characteristics vary considerably, and they experience significantly different business environments. Picard (2005) defines two significant categories of media products and services can be seen fundamentally: single creation products and continuous creation products. Depending on the media product categories, media brand content distribution and consumption changes vary; nevertheless, all media brand products are affected by technological convergence and audience fragmentation. Technologies and social media platforms development create new possibilities for media content distribution, audience reach and content consumption. The growing media content consumption via digital platforms and social media platforms, increasing media content consumption ondemand choosing a time and a platform, and the growth of mobile technologies regarding media content consumption create ample opportunities for media brands to reach the audience. Chan-Olmsted (2011) states that when branded content is accessible via multiple platforms, there are more brand touchpoints and better responsiveness to consumer needs. Social media platforms present opportunities to distribute content to the broader audience, deepen relationships with the existing audience. Due to the nature of media products as experience goods, recommendations on social networks are crucial and can help media brands reach new audiences (Rohn, Baumann, 2015).

As a result, national digital news media brands develop new content distribution and consumption patterns in volume, platforms, devices, and time. For example, in 2016, Facebook generated 30\% of the total visits for 37 American and European news websites (Piechota, 2016, p.48). In early 2018, Facebook was the leading social media traffic source (Myllylahti, 2018).

In the last years, above $50 \%$ of national news media content was accessed and consumed through social networking sites and mobile platforms, increasing non-direct and referral audience traffic while decreasing direct visits to media brands (Dentsu Aegis Network Latvia, 2017). The growing content consumption and audience share on social network sites reached $77 \%$ daily reach from all Latvian audiences in 2021 and almost $85 \%$ weekly reach from all Latvian audiences in 2021 . The daily audience reach via social media platforms increased from $65 \%$ in 2018 to $77 \%$ in 2021.

Technology convergence and social media platforms present opportunities for content distribution and audience reach, in the meantime, bring challenges for national digital news media brands. The audience patterns in content consumption change. The audience more and more switches their content usage from traditional media to social media platforms. For example, comparing the data about national media online sites 2014 and 2021, the share of audience visits decreased by $12 \%$ and compared the share of audience visits for international media brands and social media platforms increased by $14 \%$ (see Fig. 4 ).

We can see that national news media share of visits decreases over the years while the number of visits for international and social media platforms increases significantly. 
It means that social media platforms bring ample opportunities to media brands and cannibalisation of national media audience volumes.

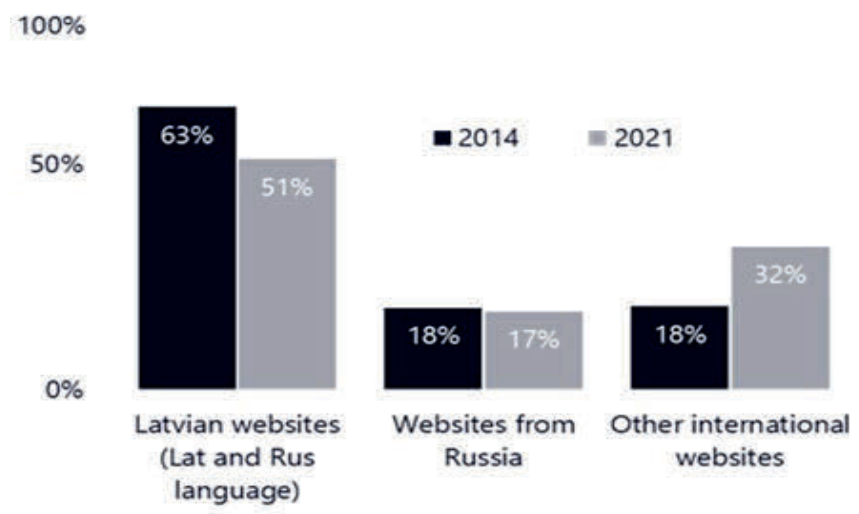

Fig. 4. Share of website visits 2014 and 2021, base: All 15-64

(Consumer Connection system, Dentsu Aegis Network Latvia, 2021)

\section{Background of media content consumption by Generation $Z$}

The media consumption habits for a younger audience (15-24 y.o.), generation Z, differ from universe data in Latvia. According to Saulite et al. (2020), the younger audience in Latvia consumes traditional media below average and prefer media content on online platforms; they choose international media and social network platforms over local media content. The younger audience's higher share of audience visits belongs to international media brands (see Fig. 5).

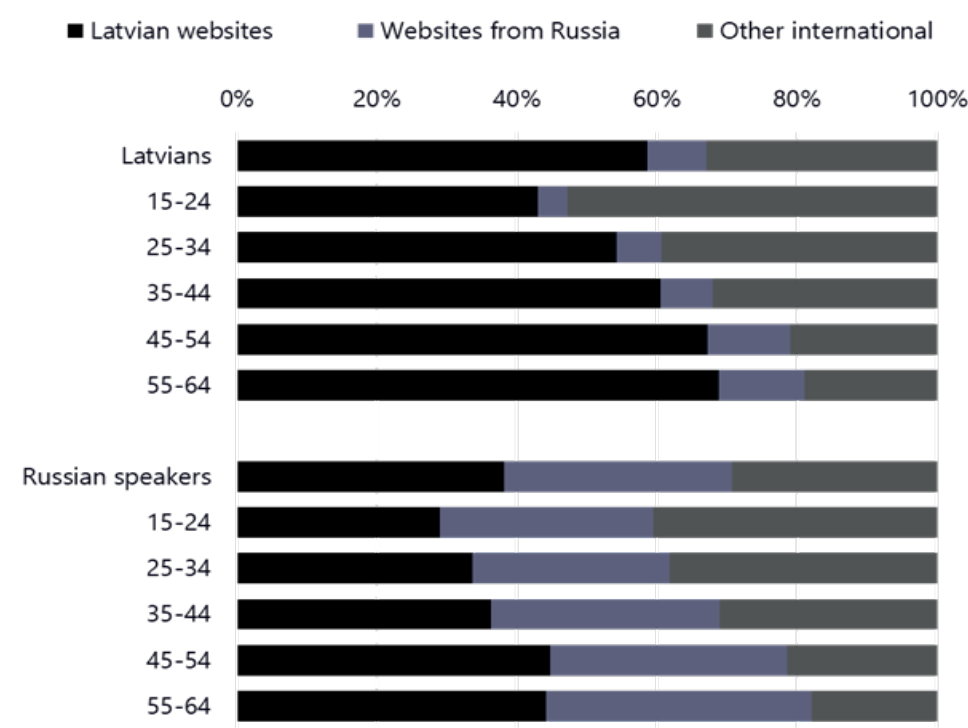

Fig. 5. Share of audience visits by age groups, Latvia base: all 15-64 (Consumer Connection system, Dentsu Aegis Network Latvia, 2021)

Also, globally for Generation Z, however, there were distinct differences. Playing video games was their favourite activity $(26 \%)$, followed by listening to music $(14 \%)$, browsing the internet (12\%), and engaging on social platforms (11\%). Only $10 \%$ of Generation Z said that watching TV or movies at home was their favourite form of entertainment (Deloitte's Center for Technology, Media \& Telecommunications, 2021). One o the more extensive researches recently done by Reuters Institute for the Study of 
Journalism (2019) found that younger audiences are different from older groups not just in what they do, but in their core attitudes regarding what they want from the news. The younger generation is primarily driven by progress and enjoyment in their lives, which translates into what they look for in the news. They still need and want, but they do not necessarily see the traditional media as the best or only way to do that. To summarise, how news brands and young people view the role and value of news are different. Traditional news brands see news as what you should know. Young audiences see news as what you should know (to an extent), useful, interesting, and fun to know. The data highlight that Generation $Z$ is very reliant on mobile and spend much time with a wide range of different social networks. The Reuters study (2019) also revealed that the differences in the relationships young people have with the news depend on three key areas: the moment of consumption, the person and the medium.

\section{The role of media audience role in media consumption}

The media audience evaluates the media based on their respective users. The recipients need to know about their fellows. They want to identify with them; they do not want a possibly negative user image to reflect on themselves. (Scherer, 2015) define that media audience becomes an integral part of a media brand. A literature overview shows that media use represents social distinction and that other persons are judged based on their media use. Bourdieu (1982) states that media use is a part of our lifestyle and an expression of habitus. Different social groups are characterised by different media use. This is a well-known fact and can be clearly analysed by grouping media audiences by their beliefs and attitudes into so-called social bubbles. Living in bubbles is the natural state of affairs for human beings. We unfriend those whose opinion elicits a breathy scoff until a feeling of contentment sets in as we resume scrolling through a curated feed of like-minded friends, highly targeted advertisements and news that fits our views. No socio demographical parameter can predict which bubble someone belongs to. However, the combination of several factors, like age, residence, and education, can.

The figure below shows two different audience segments build according to both demographics, beliefs and statements the audience agrees. These two audience segments are groups in two central bubbles: stability and tradition-oriented audience and progress and open-minded oriented audience. In Latvia, 158000 people belong to the stability and tradition audience bubble or $13 \%$ of all $15-64.118000$ people $10 \%$ of all media audience 15-64 belongs to progress and open-minded audience bubble ( Dentsu Aegis Network Latvia, 2021). Of course, there are duplications between audiences to some extend. As we can see, age plays a role when analysing social audience bubbles by age group. The younger the audience, the more open-minded and progressive they are (see Fig. 6).

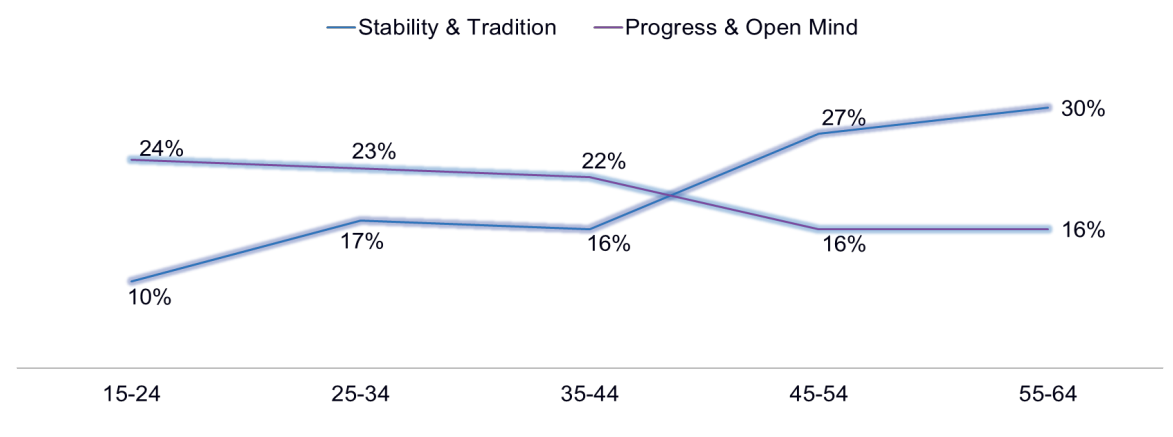


Fig. 6. Audience social bubbles by ages groups, Latvia, base all 15-64

(Consumer Connection System, Dentsu Aegis Network Latvia, 2021)

Both bubbles have somewhat different sources of information and communication habits in a social environment to confirm or approve their needs and beliefs. The uses and gratifications theory (Bulmer, Katz,1974) suggests that media users actively choose and use the media. The theory suggests that the audience seeks out the media source that best fulfils their needs. Data shows that while Traditionalists stick to classical media channels like TV and Radio, Progressive Thinkers prefer digital to consume video and music content on demand (see Fig. 7).

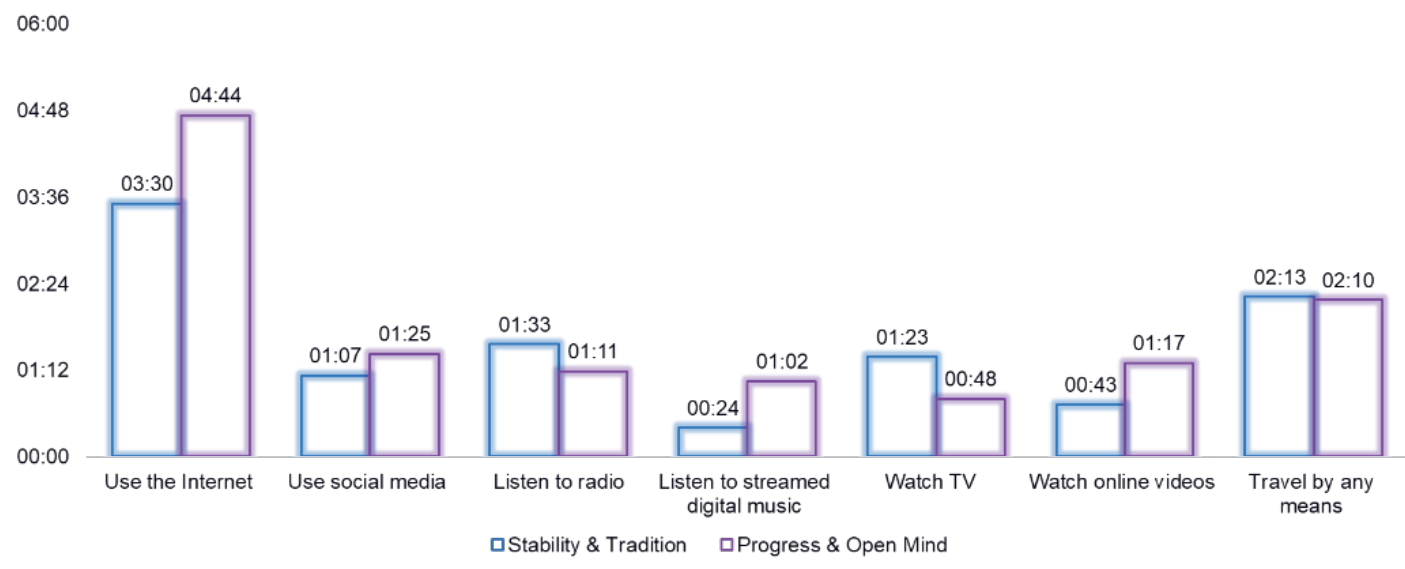

Fig. 7. Media usage by types, Latvia, base all 15-64

(Consumer Connection System, Dentsu Aegis Network Latvia, 2021)

People use media to convey to others an image of their personality. In doing so, they communicate which social groups they belong to and which they distance themselves from. Consequently, media are used for distinction. With growing audience shares on social media platforms and those platforms development, media and especially social media serve as symbolic self-completion and impression management. If to look at social media behaviour from an audience perspective using audience social bubbles, Progressive Thinkers are active social platforms users. They also tend to create their content more often compared to Traditionalists (see Fig. 8).

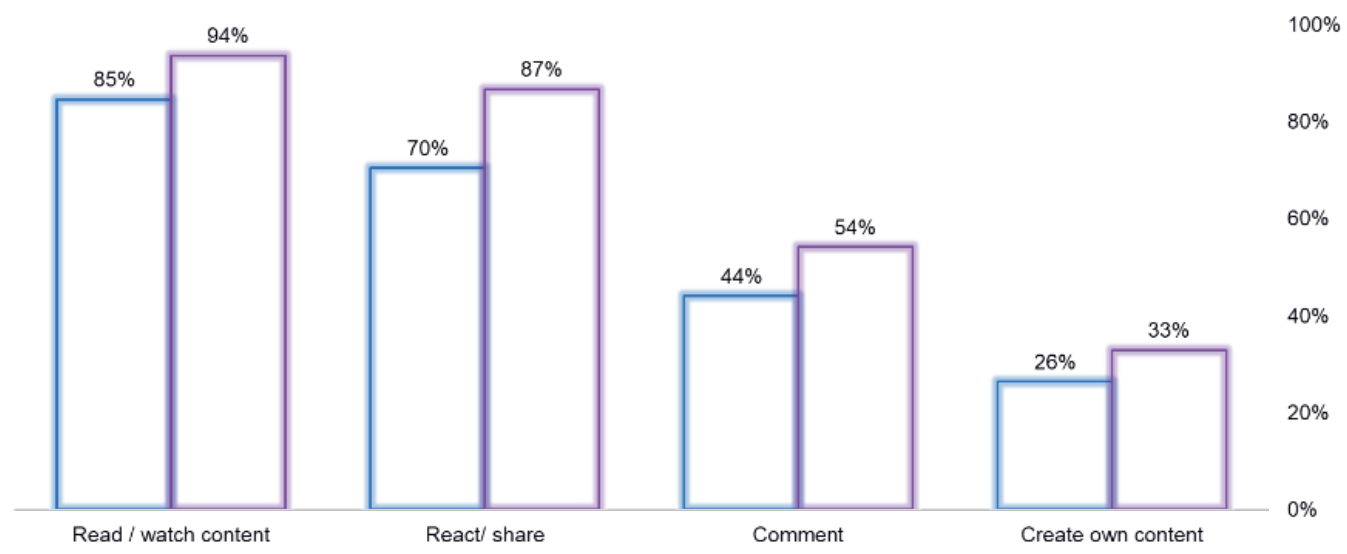

Fig. 8. Audience social bubbles social media behaviour segments, Latvia, base all 1564 (Consumer Connection System, Dentsu Aegis Network Latvia, 2021) 
The media use of individuals is one of the attributes that can be employed to judge others. We are socially evaluated based on our media use. Audiences are now visibly taking part in creating media brands, and media branding is concerned with managing this challenging process. This includes in media branding the vital attribute - the audience's image or user imagery attribute.

\section{AUDIENCE AS A PART OF MEDIA BRAND - USAGE IMAGERY OR CONTENT EXPERIENCE AND USER IMAGERY ATTRIBUTE ROLE IN MEDIA BRAND}

The increasing media consumption usage online via multiple platforms provides more access points but also deluding media brand associations, the power of audience as a part of media brand and the role for content experience in media brand associations requires for marketers to research what media brand elements are crucial in nowadays interactive and changing marketplace. Keller and Lehmann (2020) research shows that when evaluating elements of a brand that impact brand strength, we can divide elements into three main sections: brand image or customer beliefs and thoughts about the brand; brand awareness or customer knowledge about the brand; and third, customer response to the brand. The critical brand element is brand equity that combines all mentioned elements and creates intangible or added value for the brand. Brand equity is defined as this intangible or added value of the brand. High brand equity combines brand elements such as logo, product, name, attributes, marketing activities, unique brand associations, and brand image in customer minds. Customer-based brand equity occurs when the consumer is familiar with the brand and holds some favourable, strong, and unique brand associations in memory (Keller, 1993, p.1-22). According to Keller (1993) unique brand associations are the key element of building consumer-based substantial brand equity.

The research focuses on aspects of media brand associations that positively impact brand image and usage. The level of favourability, strengths and uniqueness of associations determines the brand association's impact on brand image and audience attitude toward the media brand. Due to the decrease of media brand associations when content consumption occurs via multiple platforms (Saulite et al., 2020) and the increase of global media brand usage and low level of local media brand usage and image, there is a need to revaluate media brand-building strategies via association towards a younger audience.

The author used quantitative research, survey research, a sample size of 300 respondents aged 15-24 years, weighted data in Latvia in May- June 2018. The author chose the most used local news media brands aged $15-24$ to determine non-product related brand associations that increase media brand consumption and engagement. The research built on choice questionaries to determine how Generation $\mathrm{Z}$ uses national media and access particular media brands. The research aim was to find the media brand associations that first influence media brand choice, then increase usage and engagement with the brand. The fieldwork and data analyses were done over two months, May - June 2018. First, the responders graded the importance of selected brand associations that increase content consumption, engagement and following social networks. Then the data were analysed and correlated between the main product and non-product associations determined to observe variables to establish a statistically corresponding relationship between them. The aim was to identify variables that have some ties to create. The research data confirmed two non-product related attributes that 
positively influence media brand associations and, therefore, media consumption. These are user imagery and usage imagery.

Media brand user imagery and usage imagery on social network sites build the favorability and strength of media brand associations. These are user imagery, which strongly correlates with a positive brand image and higher media usage. Keller (1993) defines user imagery association as what type of person uses the product or service, and usage imagery is association connected where and in what kinds of situations the product or service is used. User and usage imagery attributes can be formed directly from a consumer's own experiences and contact with brand users or indirectly by depicting the target market as communicated in brand advertising or other sources of information. Associations of a typical brand user may be based on demographic factors, psychographic factors and other factors. Associations of a typical usage situation may be based on the time of day, week, or year, the location (Keller, 1993, p.1-22). Media branding has changed from identifying to creating an emotional attachment with the customer. This emotional relationship creates a unique brand value for their customers, conveyed through interactive and innovative communication processes (Beig \& Nika, p. 410-417). The scholars state that to create and strengthen a unique brand impression in customers' minds, the brand narrative should be communicated through interactive ways, which creates a distinctive customer experience. The overall customer experience is pivotal in forming a deep emotional bond with a brand, resulting in a solid customerbrand relationship (Fournier, 1998, p. 343-373). Customer experience has been used to improve mass customised products (Addis \& Holbrook, 2001) and deliver a genuine customer value (Prahalad \& Ramaswamy, 2004). Consumption experience is defined as the perfect basis for brand differentiation and distinctiveness (Pine \& Gilmore, 1999; Schmitt, 1999).

User and usage of image attributes can also produce brand personality attributes. For example, the media brand user profile or community image contributes to the more favourable, durable and unique media brand association. Furthermore, the more the target audience feels connected, engaged and associated with the media brand audience community, the positive it feels towards the media brand (Saulite et al., 2020). Thus, the research confirms many scholars finding that audience becomes a significant part of media brand and interaction or content experience is crucial for building media brand associations. Furthermore, the engagement model data shows that the distinctiveness of media brand products on social media influences media brand engagement. These two attributes - audience perception and consumption experience (formats, way of delivery) correlate with Generation Z's higher media brand usage and engagement.

\section{CONCLUSION}

These findings are critical to review and adapt media branding systems in a new way. The distribution drivers positively affect supply efficiency to the audience, and from the other side, this efficiency negatively influences media brand associations and, therefore, brand equity. The necessity for content branding experience via different platforms according to unique aspects of each platform could strongly increase positive consumption experience and therefore create audience memories that strengthen brand associations and brand equity. Audience involvement and engagement in the media brand content life cycle could create more vital user imagery attributes and support audience belonging and willingness to belong to a particular media brand audience. More profound research on particular brand attributes via different platforms is needed 
to analyse and apply the new aspects of media branding in a growing digital and interactive marketplace. The limitations of this research are that only national news media or the continuous creation media were analysed. Also, the next step in particular research would be how media brand associations are influenced by media content value from the audience perspective as media. One of the media's unique properties and characteristics is that there are multiple reuses, especially for continuous creation products, for media products, and the reuses may be more valuable than the original use (Vogel, 2004). Value of media product is widely measured from a financial and economic perspective, but in literature, there is a gap in how media product reuse and increasing value affect media brand equity through consumer experience and brand associations.

\section{REFERENCES}

Addis, M., \& Holbrook, M. B. (2001). On the conceptual link between mass customisation and experiential consumption: An explosion of subjectivity. Journal of Consumer Behaviour: An International Research Review, 1(1), 50-66.

Beig, F. A., \& Nika, F. A. (2019). Brand Experience and Brand Equity. Vision, 23(4), 410-417. https://doi.org/10.1177/0972262919860963

Bourdieu, P. (1982). Die feinen Unterschiede. Kritik der gesellschaftlichen Urteilskraft. Frankfurt/M.: Suhrkamp.

Bourdieu, P. (1984). Distinction: A social critique of the judgement of taste/Pierre Bourdieu; translated by Richard Nice. Cambridge, MA: Harvard University Press

Chan-Olmsted, S. (2011) Media branding in a changing world: Challenges and opportunities 2.0. The International Journal on Media Management, 13(1), 3-19.

Consumer Connection System Latvia (2018). Dentsu Aegis Network Latvia consumer research, 20122018.

Consumer Connection System Latvia (2021). Dentsu Aegis Network Latvia, consumer research, 2012 2021.

Eremina, Y., Lace, N., Bistrova, J. (2019). Digital Maturity and Corporate Performance: The Case of the Baltic States. J. Open Innov. Technol. Mark. Complex. 5, 54. https://doi.org/10.3390/joitmc5030054

Galan, L., Osserman, J., Parker, Y., Taylor, M. (2019). How Young People Consume News and The Implications for Mainstream Media. Flamingo commissioned by the Reuters Institute for the Study of Journalism, Oxford University.

Fournier, S. (1998). Consumers and their brands: Developing relationship theory in consumer research. Journal of Consumer Research, 24(4), 343-373.

Holbrook, M. B., \& Hirschman, E. C. (1982). The experiential aspects of consumption: Consumer fantasies, feelings, and fun. Journal of Consumer Research, 9(2), 132-140.

India, D. T. (2015). Digital Media: The rise of On-demand Content.

Jenkins, H. (2006) Convergence Culture: Where Old and New Media Collide. New York University Press.

Katz, E., Blumler, J. G., \& Gurevitch, M. (1973-1974). Uses and gratifications research. Public Opinion Quarterly, 37(4), 509-523. https://doi.org/10.1086/268109

Keller, K.L. (2001). Building customer-based brand equity: A blueprint for creating strong brands, Management Science Institute, 1(107), 1-31.

Myllylahti, M. (2018). An attention economy trap? An empirical investigation into four news companies Facebook traffic and social media revenue. Journal of Media Business Studies, 15(4), 237-253.

Picard, R. G. (2005). Unique Characteristics and Business Dynamics of Media Products. Journal of Media Business Studies, 2(2), 61-69.

Rohn, U., Baumann, S. (2015). Media brands in social network sites: Problems German media companies have faced and lessons they have learned. Journal of Brand Strategy, 4(1), 70-82.

Saulite, L., Janusevska, G., Andersone, I., \& Sceulovs, D. (2020). Trends in Media Branding: Case of Latvia. The Younger Audience in Focus. Winter Garden, Florida: International Institute of Informatics and Systemics (IIIS), 3, 98-102.

Scherer, H. (2015). The Groucho Marx Dilemma in Media Branding: Audience as Part and Signal of Media Brands. In: Siegert G., Förster K., Chan-Olmsted S., Ots M. (eds) Handbook of Media Branding. Springer, Cham. https://doi.org/10.1007/978-3-319-18236-0_18 
Schmitt, B. H., \& Rogers, D. L. (2008). Handbook on brand and experience management. Northampton, MA: Edward Elgar Publishing.

Siegert, G., Förster, K., Chan-Olmsted,S.M., M. Ots, M(Eds.) (2011). Handbook of Media Branding. Springer.

Vogel, H.L. (2004). Entertainment Industry Economics: A Guide for Financial Analysis, 6th ed. Cambridge: Cambridge University Press.

Westcott, K., Arbanas, J., Downs, K., Arkenberg, K., Jarvis, D. (2021). Digital media trends, 15th ed. Courting the consumer in a world of choice. Deloitte Insights. Retrieved on 2021 June 1 from https://www2.deloitte.com/us/en/insights/industry/technology/digital-media-trends-consumptionhabits-survey/summary.html

Quantitative empirical research, a sample size of 300 respondents age group 15-24 years, weighted data, Latvia, May 2018.

\section{AUTHORS' SHORT BIOGRAPHY}

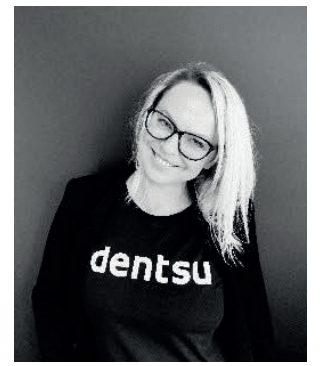

Linda Saulite received a master's degree in economics from the Stockholm School of Economics. Linda works as Research Assistant at Riga Technical University and is a $\mathrm{PhD}$ student at Riga Technical University. Her research interests are media branding and brand uniqueness aspects, particularly in brand uniqueness in the digital environment. The author is Managing Director and Member of the Board of the communication and media agency Dentsu Aegis Network Latvia.

E-mail: Linda.Saulite_1@edu.rtu.lv 